vely. By itself, this error may not appear to be large, but as it may further increase the discrepancy. found between the manometric and the photometric values, we consider that it should be avoided.

As with the existing nomogram developed by SiGGAARD-ANDERSEN, the per cent oxygen saturation scale of the nomogram presented by EHRENGRUBER in the following paper (8) must be constructed for each instrument (i. e. each set of filters) and for the species which is to be investigated. Its advantage lies in its general applicability to a two-wavelength method for the determination of the per cent oxygen saturation of different haemoglobins with interference filters, one of which has a maximum transmission close to, but not necessarily identical with the isosbestic wavelength for oxyhaemoglobin and reduced haemoglobin.

\title{
References
}

1. ZijLstrA, W. G., A manual of reflection oximetry. van Gorcum \& Co., Assen (1958). - 2. ZijLstra, W. G. and G. A. vaN Mook, Medical reflection photometry. van Gorcum \& Co., Assen (1962). - 3. WAHLEN, S., Vergleichende Messungen der Sauerstoffsättigung des Blutes mittels Hämoreflektor und Spektrophotometrie. Inaug. Diss., Bern 1966. - 4. Cole, P. V. and L. H. Hawkins, Bio-medical Engineering 2, 56 (1967). - 5.
Drabkin, D. L. and J. H. Austin, J. biol. Chemistry 112, 51 (1935). - 6. NaHAS, G. G., Science Washington 113, 723 (1951). 7. SiggaArd-Andersen, O., K. Jørgensen and N. NaeraA, Scand. J. Clin. Laborat. Invest. 14, 298 (1962). - 8. EHRENGRUBER, H., diese Z. 6, 200 (1968). 9. BretschneIder, H. J., A. FranK, E. Kanzow and U. Bernard, Pflügers Arch. Physiol. 264, 399 (1957).
PD Dr. P. Lundsgaard-Hansen Inselspital $\mathrm{CH} 3008$ Bern (Switzerland)

\section{A new Nomogram for the Calculation of Haemoglobin Oxygen Saturation by Interference Filter Photometry}

\author{
By H. Ehrengruber \\ From the Central Chemical Laboratory, Inselspital, Berne (Switzerland)
}

(Eingegangen am 13. Januar 1968)

\begin{abstract}
As shown. in the preceding paper, the standard procedure for the calculation of haemoglobin oxygen saturation by a two-wavelength method and the existing nomogram are not generally valid when interference filters are employed. A calculation procedure and a nomogram are presented which are generally valid and which can be adapted to the differences between interference filters and haemoglobins from different species.

Wie in der vorangehenden Arbeit gezeigt wurde, ist das Standardverfahren zur Berechnung der Sauerstoffsättigung des Hämoglobins nicht allgemein gültig, wenn bei zwei Wellenlängen mit Interferenzfiltern gearbeitet wird. Das gleiche gilt für das bisher vorliegende Nomogramm. Es wird ein allgemein gültiges Berechnungsverfahren und ein Nomogramm vorgelegt, die den unterschiedlichen Eigenschaften der Interferenzfilter uṇd der Hämoglobine verschiedener Spezies angepaßt werden können.
\end{abstract}

The standard formulas applicable to the determination of haemoglobin oxygen saturation by a two-wavelength spectrophotometric method are:

$$
\mathrm{O}_{2} \%=\frac{\left[\left(D_{R} / D_{G}\right)_{H b}-\left(D_{R} / D_{G}\right)_{x}\right] \cdot 100}{\left(D_{R} / D_{G}\right)_{H b}-\left(D_{R} / D_{G}\right)_{H b O}}
$$

or:

where:

$$
\mathrm{O}_{2} \%=\mathrm{A}-\mathrm{B} \cdot\left(\mathrm{D}_{\mathrm{R}} / \mathrm{D}_{\mathrm{G}}\right)_{\mathbf{x}}
$$

$$
A=\frac{\left(D_{R} / D_{G}\right)_{H b} \cdot 100}{\left(D_{R} / D_{G}\right)_{H b}-\left(D_{R} / D_{G}\right)_{H b O_{2}}}
$$

and

$$
\mathrm{B}=\frac{100}{\left(\mathrm{D}_{\mathrm{R}} / \mathrm{D}_{\mathrm{G}}\right)_{\mathrm{Hb}}-\left(\mathrm{D}_{\mathrm{R}} / \mathrm{D}_{\mathrm{G}}\right)_{\mathrm{HbO}}} .
$$

These formulas are valid only if the green wavelength $(505 \mathrm{~nm})$ equals the isosbestic point for reduced haemoglobin and oxyhaemoglobin, $\dot{i}$. e. if the ratio $D_{G}$, Hbo $_{2} /$ $D_{G}$, пь is 1.0. If this premise is not valid, as may. be the case when interference filters are employed (1), the following formula has to be used for the calculation of the per cent oxygen saturation:

$$
\begin{array}{r}
\mathrm{O}_{2} \% \frac{\left[\left(\frac{D_{R}}{D_{G}}\right)_{\text {Hb }}-\left(\frac{D_{R}}{D_{G}}\right)_{X}\right] \cdot 100}{\left(\frac{D_{R}}{D_{G}}\right)_{\text {Hb }}-\left(\frac{D_{R}}{D_{G}}\right)_{\mathrm{HbO}_{2}}+\left[\left(\frac{D_{R}}{D_{G}}\right)_{\mathrm{HbO}_{2}}-\left(\frac{D_{R}}{D_{G}}\right)_{X}\right]} \\
\cdot\left[1-\frac{D_{G}, \text { HbO }_{2}}{D_{G}, \text { Hb }}\right]
\end{array}
$$

For human blood, the following constants were found (1):

$$
\begin{aligned}
& \left(D_{R} / D_{G}\right)_{H b}=0.567 ;\left(D_{R} / D_{G}\right)_{H b O_{2}}=0.129 ; \\
& \mathrm{D}_{G, \text { HВO }_{2}} / \mathrm{D}_{\mathrm{G}, \text { 耳b }}=1.08 \text {. }
\end{aligned}
$$

Since the calculation of oxygen saturation by equation [2] is very cumbersome, a simpler computing formula is desirable. By inserting the constants given above in equation [2], we obtain (after transforming the denominator):

$$
\mathrm{O}_{2} \%=\frac{0.567-\left(D_{R} / D_{G}\right)_{x}}{0.428-0.08\left(D_{R} / D_{G}\right)_{x}} \cdot 100
$$


Similar formulas are obtained for dog and rabbit blood, if the constants given in Table 1 of the preceding paper (1) are inserted into equation [2].

\section{Deduction of a computing formula}

The term $\left(D_{R} / D_{G}\right)_{x}$ is the ratio of the optical densities of the unknown sample at 600 and $505 \mathrm{~nm}$, respectively. Therefore, the numerator and the denominator of equation [3] can be multiplied by $D_{G}$, which gives:

$$
\mathrm{O}_{2} \%=\frac{0.567 \mathrm{D}_{\mathrm{G}}-\mathrm{D}_{\mathrm{R}}}{0.428 \mathrm{D}_{\mathrm{G}}-0.08 \mathrm{D}_{\mathrm{R}}} \cdot 100
$$

The optical density $\mathrm{D}$ is the measured extinction $\mathrm{E}$ of the cuvette filled with haemolyzed blood minus the water blank $\mathrm{E}_{\mathrm{H}_{2} \mathrm{O}}$ of the cuvette at the same wavelength, or:

$$
D_{R}=E_{R}-E_{\mathrm{H}_{2} \mathrm{O}, \mathrm{R}} \text { and } \mathrm{D}_{\mathrm{G}}=\mathrm{E}_{\mathrm{G}}-\mathrm{E}_{\mathrm{H}_{8} \mathrm{O}, \mathrm{G} .}
$$

Thus, we may also calculate the per cent oxygen saturation directly from the measured extinctions. With $\mathrm{E}_{\mathrm{H}_{2} \mathrm{O}, \mathrm{R}}=0.041$ and $\mathrm{E}_{\mathrm{H}_{2} \mathrm{O}, \mathrm{G}}=0.038$, the following formulas for the calculation of the oxygen saturation of the unknown sample were obtained and utilized for the calculations described in the preceding paper (1):

$$
\begin{aligned}
\text { Man: } O_{2} \% & =\frac{0.567 E_{G}-E_{R}+0.019}{0.428 E_{G}+0.08 E_{R}-0.020} \cdot 100 \\
\text { Dog: } O_{2} \% & =\frac{0.550 E_{G}-E_{R}+0.020}{0.411 E_{G}+0.11 E_{R}-0.020} \cdot 100 \\
\text { Rabbit: } O_{2} \% & =\frac{0.517 E_{G}-E_{R}+0.021}{0.389 E_{G}+0.08 E_{R}-0.018} \cdot 100
\end{aligned}
$$

Without inserting definite numerical values, the transformation of equation [2] yields the following general computing formula:

$$
\mathrm{O}_{2} \%=\frac{a E_{G}-E_{R}+b}{c E_{G}+d E_{R}-e} \cdot 100
$$

where

$$
\begin{aligned}
& \mathrm{a}=\left(\mathrm{D}_{\mathrm{R}} / \mathrm{D}_{\mathrm{G}}\right)_{\mathrm{Hb}} \\
& \mathrm{b}=\mathrm{E}_{\mathrm{H}_{2} \mathrm{O}, \mathrm{R}}-\mathrm{E}_{\mathrm{H}_{2} \mathrm{O}, \mathrm{G}} \cdot\left(\mathrm{D}_{\mathrm{R}} / \mathrm{D}_{\mathrm{G}}\right)_{\mathrm{Hb}} \\
& c=\left(D_{R} / D_{G}\right)_{\text {Hb }}-\left(D_{R} / D_{G}\right)_{\text {HbO }} \cdot\left(D_{G}, \text { Hbо }_{2} / D_{G}, H_{b}\right) \\
& \mathrm{d}=\left(\mathrm{D}_{\mathrm{G}}, \mathrm{H}_{\mathrm{b}} / \mathrm{D}_{\mathrm{G}}, \mathrm{Hb}_{\mathrm{b}}\right)-1 \\
& e=c \cdot E_{H_{2} \mathrm{O}, G}+d \cdot E_{H_{2} \mathrm{O}, R} \text {. }
\end{aligned}
$$

The constants $a, b, c, d$ and e must be calculated from the individual apparatus constants. This being done and their numerical values inserted into equation [6], a computing formula is obtained which simplifies the calculation of the per cent oxygen saturation- of an unknown sample as compared to equation [2].

\section{Construction of a nomogram}

\section{General considerations}

Instead of calculating the oxygen saturation by formula [6], we may also construct a nomogram by means of which the per cent oxygen saturation can be directly read from the optical densities $D_{R}$ and $D_{G}$. First, some mathematical considerations pertaining to the problem:
Equation [3] shows that the per cent oxygen saturation is a function of the ratio $D_{R} / D_{G}$ of the optical densities. The general form of a relation of this type is:

$$
\mathrm{O}_{2} \%=\frac{A+B \cdot\left(D_{R} / D_{G}\right)}{C+D \cdot\left(D_{R} / D_{G}\right)}
$$

In our applications of equation [7], A, B, C and D show that

$$
\begin{aligned}
& A=100 \cdot\left(D_{R} / D_{G}\right)_{\text {H }} \\
& B=-100 \\
& C=\left(D_{R} / D_{G}\right)_{H b}-\left(D_{R} / D_{G}\right)_{\text {Hb }_{2}} \cdot\left(D_{G}, \text { H }_{2} / D_{G}, \text { Hb }\right) \\
& D=\left(D_{G}, \text { HbO }_{2} / D_{G}, \text { Hb }\right)-1 .
\end{aligned}
$$

Equation [3] is rederived from [7] with $A=56.7$, $B=-100, C=0.428$ and $D=0.08$. In the special case of $\left(\mathrm{D}_{\mathrm{G}}, \mathrm{HbO}_{2} / \mathrm{D}_{\mathrm{G}, \mathrm{Hb}}\right)$ being equal to 1.0 , equation [7] leads back to equation [1], since, in this case, we have $\mathrm{D}=0$ and $\mathrm{C}=\left(\mathrm{D}_{\mathrm{R}} / \mathrm{D}_{\mathrm{G}}\right)_{\text {Hb }}-\left(\mathrm{D}_{\mathrm{R}} / \mathrm{D}_{\mathrm{G}}\right)_{\text {Hb }}$.

If the ratio $D_{R} / D_{G}$ is known, the per cent oxygen saturation can be calculated from equation [7]. Denoting this ratio by $u$, i. e. $u=D_{R} / D_{G}$, equation [7] can be written in the form

$$
\mathrm{O}_{2} \%=\frac{\mathrm{A}+\mathrm{Bu}}{\mathrm{C}+\mathrm{Du}}
$$

Now, the calculation of the per cent oxygen saturation can be subdivided into two steps:

- calculation of the ratio $u$ from $D_{R}$ and $D_{G}$

- calculation of $\mathrm{O}_{2} \%$ from $\mathrm{u}$, using equation [8].

The construction of the nomogram also follows these two steps: First, a nomogram for the ratio $u$ of the optical densities $D_{R}$ and $D_{G}$ is constructed; then the $u$-scale is recalibrated so that the value "per cent oxygen saturation" can be read directly, $\mathrm{O}_{2} \%$ being expressed as a function of $u$ by equation [8].

As shown in Figure 1, the nomogram consists of three parallel straight lines, representing the $D_{R^{-}}$, the $\mathrm{D}_{\mathrm{G}^{-}}$and the u-scale. This arrangement of the scales assures maximum accuracy of reading obtainable with a nomogram. Position and calibration of the scales permit the reading-off of the ratio $D_{R} / D_{G}$ on the uscale if the measured values of $D_{R}$ and $D_{G}$ on the respective scales are connected by a ruler.

To construct such a nomogram, the values not of $D_{R}$, $D_{G}$ and $u$, but those of certain logarithmic functions of these quantities must be plotted on the scales. The mathematical details of the construction are given in the appendix.

\section{Re-calibration of the u-scale}

Actually, we are not interested in the ratio u itself, but in the quantity "per cent oxygen saturation", which can be calculated as a function of $\mathrm{u}$ according to equation [8]. Hence, it is not the values of $u$ that are plotted on the u-scale, but the values of $\mathrm{O}_{2} \%$ calculated from $u$ by equation [8]. If, for example, $D_{R}$ is 0.4 and $D_{G} 0.8$, the ratio has the value 0.5 . When the points 0.4 on the $D_{R}$-scale and 0.8 on the $D_{G}$-scale are connected by a ruler, the u-scale is intersected at a point $u_{0}$. At this 


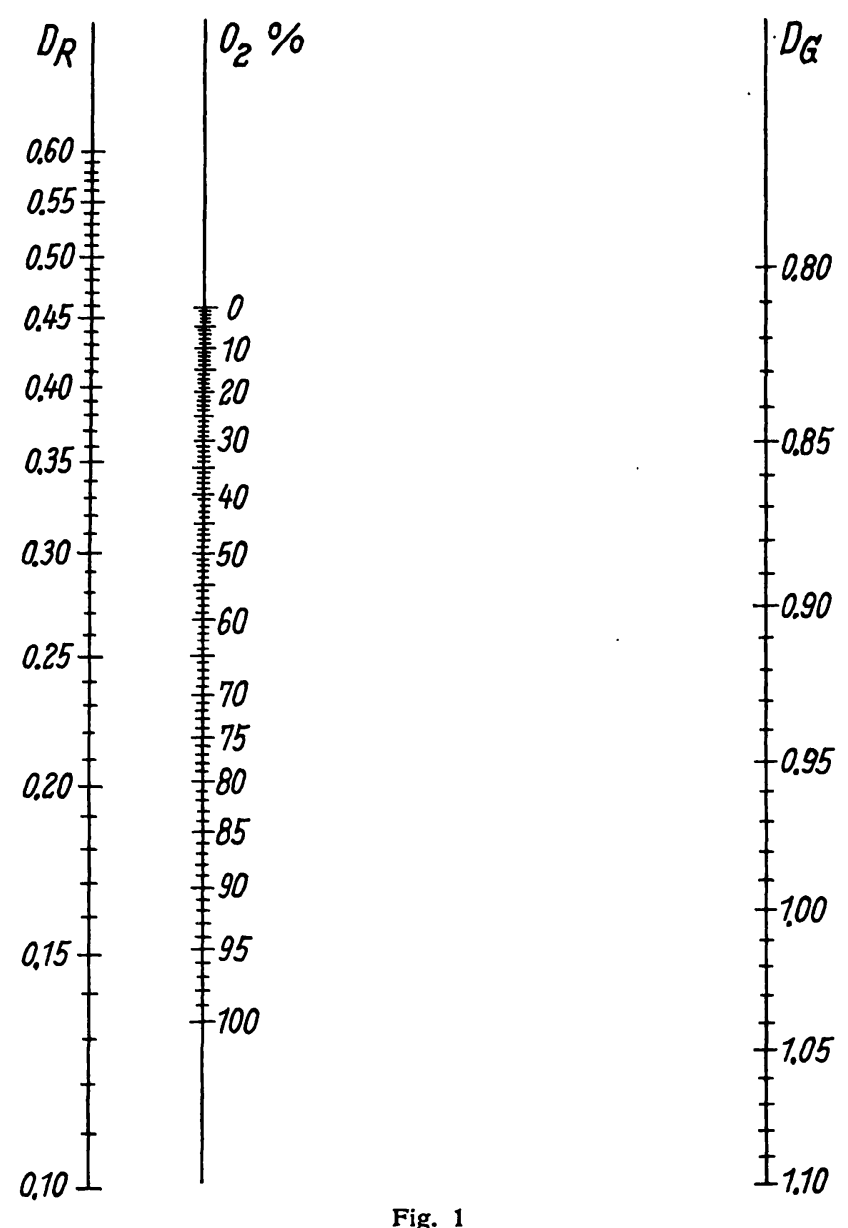

Nomogram for the calculation of haemoglobin oxygen saturation of normal, adult human blood by a two-wavelength method based on interference filter photometry. Note: The middle scale must be specified for each set of filters and for haemoglobins from different species
file

point $u_{0}$, we plot not the value 0.5 for $u$, but the value for $\mathrm{O}_{2} \%$ calculated by [8]:

$$
\mathrm{O}_{2} \%=\frac{\mathrm{A}+\mathrm{B} \cdot 0.5}{\mathrm{C}+\mathrm{D} \cdot 0.5}
$$

Thus it is possible to read directly the oxygen saturation corresponding to $\mathrm{D}_{\mathrm{R}}=0.4$ and $\mathrm{D}_{\mathrm{G}}=0.8$.

\section{Application of the method}

The advantage of the method outlined here is that the first step, i. e. the construction of the nomogram for $u$, does not depend on the quantities $A, B, C$ and $D$ specified under equation [7]. In other words, the parameters determined in the first step of the procedure are independent of the individual apparatus constants. The basic nomogram once constructed, it can be adapted to any set of filters and any kind of haemoglobin simply by performing the second step, i. e. by fixing the calibration of the middle scale.

In the first step of the construction procedure, the following parameters of the nomogram are determined (cf. Fig. 1 and appendix):

\section{1: Position of the scales:}

Distance between $D_{R^{-}}$and $D_{G^{-}}$scale $=15.0 \mathrm{~cm}, D_{R}$ to the left.

Distance between $D_{R^{-}}$and $u-s c a l e=2.5 \mathrm{~cm}$, with $u$ to the right of $D_{R}$.

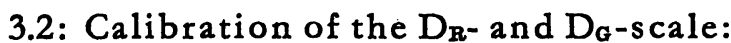

In the case treated here, the ranges for $D_{R}$ and $D_{G}$ are $0.1-0.6$ and $0.8-1.1$, respectively. The individual values within these ranges are plotted on the scales according to the following formulas:

Distance in $\mathrm{cm}$ of any $\mathrm{D}_{\mathrm{R}}$-value $\mathrm{x}$ above the baseline of the nomogram:

$$
h_{R}(x)=30 \log 10 x
$$

Distance in $\mathrm{cm}$ of any $\mathrm{D}_{\mathrm{G}}$-value $\mathrm{y}$ above the baseline of the nomogram:

$$
h_{G}(y)=150 \log \frac{1.1}{y}
$$

Note that the $D_{G}$-values increase from above downwards. If other ranges for $D_{R}$ and $D_{G}$ are to be covered, the formulas [9a] and [9b] for $h_{R}$ and $h_{G}$ must be specially calculated.

\section{3: u-scale measure:}

Distance in $\mathrm{cm}$ of any value $\mathrm{u}$ above the baseline of the nomogram:

$$
h(u)=25 \log 11 u
$$

Note that the u-scale is not yet calibrated, since the saturation values $\mathrm{O}_{2} \%$, which are dependent on $A, B, C$ and $D$, are to be plotted here.

In the formulas [9a], [9b] and [10], the symbol log means commom logarithms. For example, the distance of $\mathrm{D}_{\mathbf{R}}=0.1$ above the baseline is:

$$
\mathrm{h}_{\mathrm{R}}(0.1)=30 \log 10 \cdot 0.1=30 \log 1=0 .
$$

Similarly, the distance of $D_{G}=1.1$ above the baseline is:

$$
h_{G}(1.1)=150 \log \frac{1.1}{1.1}=150 \log 1=0
$$

The parameters given above are the same for any apparatus as long as $D_{R}$ and $D_{G}$ remain within the ranges $0.1-0.6$ and $0.8-1.1$, respectively. This condition will be fulfilled if the oxygen saturation meter OSM ${ }^{1}$ ) is handled as recommended in the instruction manual.

The distances in $\mathrm{cm}$ from the baseline of the nomogram

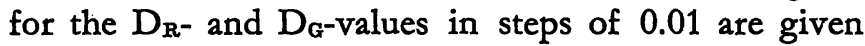
in Tables 1 and 2 . The calculation was done by computer with a simple Fortran program.

The scales for $D_{R}$ and $D_{G}$ are calibrated by means of Tables 1 and 2. The position and distance of the scales were specified under 3.1 and the appearance of the nomogram is illustrated by Figure 1 . The only thing. remaining to be done is to specify the middle scale according to the individual apparatus constants, which -vary with filters and haemoglobins (1).

\section{Specification of the middle scale}

The calibration of the middle scale is dependent on the quantities $A, B, C$ and $D$, the meaning of which was defined under equation [7]. If their numerical values

i) Radiometer, Copenhagen. 
Tab. 1

$\mathrm{D}_{\mathrm{R}^{\text {-scale }}}$

\begin{tabular}{cccc}
\hline $\mathrm{D}_{\mathbf{R}}$ & $\begin{array}{c}\text { cm above } \\
\text { baseline }\end{array}$ & $\mathrm{D}_{\mathbf{R}}$ & $\begin{array}{c}\text { cm above } \\
\text { baseline }\end{array}$ \\
\hline 0.10 & 0.00 & 0.36 & 16.69 \\
0.11 & 1.24 & 0.37 & 17.05 \\
0.12 & 2.38 & 0.38 & 17.39 \\
0.13 & 3.42 & 0.39 & 17.73 \\
0.14 & 4.38 & 0.40 & 18.06 \\
0.15 & 5.28 & 0.41 & 18.38 \\
0.16 & 6.12 & 0.42 & 18.70 \\
0.17 & 6.91 & 0.43 & 19.00 \\
0.18 & 7.66 & 0.44 & 19.30 \\
0.19 & 8.36 & 0.45 & 19.60 \\
0.20 & 9.03 & 0.46 & 19.88 \\
0.21 & 9.67 & 0.47 & 20.16 \\
0.22 & 10.27 & 0.48 & 20.44 \\
0.23 & 10.85 & 0.49 & 20.71 \\
0.24 & 11.41 & 0.50 & 20.97 \\
0.25 & 11.94 & 0.51 & 21.23 \\
0.26 & 12.45 & 0.52 & 21.48 \\
0.27 & 12.94 & 0.53 & 21.73 \\
0.28 & 13.41 & 0.54 & 21.97 \\
0.29 & 13.87 & 0.55 & 22.21 \\
0.30 & 14.31 & 0.56 & 22.45 \\
0.31 & 14.74 & 0.57 & 22.68 \\
0.32 & 15.15 & 0.58 & 22.90 \\
0.33 & 15.56 & 0.59 & 23.13 \\
0.34 & 15.94 & 0.60 & 23.34 \\
0.35 & 16.32 & & \\
\hline
\end{tabular}

Tab. 2

$D_{G}$-scale

\begin{tabular}{cccc}
\hline$D_{\mathbf{G}}$ & $\begin{array}{c}\text { cm above } \\
\text { baseline }\end{array}$ & $\mathrm{D}_{\mathbf{G}}$ & $\begin{array}{c}\text { cm above } \\
\text { baseline }\end{array}$ \\
\hline 0.80 & 20.75 & 0.96 & 8.87 \\
0.81 & 19.94 & 0.97 & 8.19 \\
0.82 & 19.14 & 0.98 & 7.52 \\
0.83 & 18.35 & 0.99 & 6.86 \\
0.84 & 17.57 & 1.00 & 6.21 \\
0.85 & 16.80 & 1.01 & 5.56 \\
0.86 & 16.03 & 1.02 & 4.92 \\
0.87 & 15.28 & 1.03 & 4.28 \\
0.88 & 14.54 & 1.04 & 3.65 \\
0.89 & 13.80 & 1.05 & 3.03 \\
0.90 & 13.07 & 1.06 & 2.41 \\
0.91 & 12.35 & 1.07 & 1.80 \\
0.92 & 11.64 & 1.08 & 0.20 \\
0.93 & 10.94 & 1.09 & 0.09 \\
0.94 & 10.24 & 1.10 & \\
0.95 & 9.55 & & \\
\hline
\end{tabular}

are inserted into equation [8], we obtain the basic computing formula for the per cent oxygen saturation $\left(\mathrm{O}_{2} \%\right)$ as a function of $u$. The middle scale of the nomogram is specified according to this formula. As an example, we may take the apparatus constants - given for human blood in the preceding paper (1): $\left(\mathrm{D}_{\mathrm{R}} / \mathrm{D}_{\mathrm{G}}\right)_{\text {Hъ }}=0.567,\left(\mathrm{D}_{\mathrm{R}} / \mathrm{D}_{\mathrm{G}}\right)_{\text {H }_{\mathrm{B}}}=0.129$ and $\left(\mathrm{D}_{\mathrm{G}}, \mathrm{HbO}_{2} / \mathrm{D}_{\mathrm{G}}, \mathrm{Hb}\right)=1.08$. From these, we obtain $\mathrm{A}=56.7, \mathrm{~B}=-100, \quad \mathrm{C}=0.428$ and $\mathrm{D}=0.08$. Inserting those values into equation [8], we have:

$$
\mathrm{O}_{2} \%=\frac{56.7-100 \mathrm{u}}{0.428+0.08 \mathrm{u}}
$$

Now, we want the middle scale to yield the per cent values of the oxygen saturation directly. Hence, the positions of the per cent values $0,1,2, \ldots .98,99,100$ have to be calculated. Let $z$ denote one of these per cent values. Then there is exactly one value of $u$ which yields $z$ as a result when inserted into equation [8]. For instance, in the example of formula [11], the value of $u$ corresponding to $z=100$ is 0.129 , or $\left(D_{R} / D_{G}\right)_{\text {Hroz }}$ :

$$
\mathrm{O}_{2} \%=\frac{56.7-100 \cdot 0.129}{0.428+0.08 \cdot 0.129}=\frac{43.8}{0.438}=100
$$

Generally, the u-values corresponding to a given per cent oxygen saturation are obtained by solving equation [8] for $u$, which gives:

$$
\mathrm{u}=\frac{\mathrm{A}-\mathrm{C} \cdot \mathrm{O}_{2} \%}{-\mathrm{B}+\mathrm{D} \cdot \mathrm{O}_{2} \%}
$$

Thus by inserting the numbers $0,1,2, \ldots \ldots 98,99,100$ into equation [12], we obtain the corresponding values for $u$. The distance in $\mathrm{cm}$ above the baseline of the nomogram of the per cent vaule $z$ on the middle scale is now found by inserting the corresponding value for $u$ into equation [10]:

$$
\mathrm{h}(\mathrm{u})=25 \log 11 \mathrm{u} \text {. }
$$

Returning to the example just given, we have $z=100$ and $\mathrm{u}=0.129$. Then

$$
\mathrm{h}(0.129)=25 \log 11 \cdot 0.129=25 \log 1.419=3.80 \text {. }
$$

Hence, $\mathrm{O}_{2} \%=100$ is plotted on the middle scale $3.80 \mathrm{~cm}$ above the baseline. The calculations of $u$ and $\mathrm{h}$ (u) can be performed with a standard calculating machine. This may represent a day's work, but the labour involved is amply rewarded by the ease with which the oxygen saturation of heamoglobin is subsequently obtained.

To sum up, the final nomogram is obtained as follows: 1. Determine the constants $\left(D_{R} / D_{G}\right)_{H b},\left(D_{R} / D_{G}\right)_{\text {H bо }}$ and $\left(\mathrm{D}_{\mathrm{G}, \mathrm{BbO}} / \mathrm{D}_{\mathrm{G}, \mathrm{Bb}}\right)$ for the interference filter photometer and the haemoglobin of the species with which the laboratory intends to work (1).

2. Prepare the basic nomogram as outlined in the present paper.

3. Calculate the quantities $A, C$ and $D$ from the constants established. $B$ is a constant and $=-100$.

4. Calculate the values for $u$ corresponding to the per cent oxygen saturation from 0 to 100 according to equation [12]. $\mathrm{u}_{0}=\left(\mathrm{D}_{\mathrm{R}} / \mathrm{D}_{\mathrm{G}}\right)_{\mathrm{Hb}}$ and $\mathrm{u}_{100}=\left(\mathrm{D}_{\mathrm{R}} /\right.$ $\left.\mathrm{D}_{\mathrm{G}}\right)_{\mathrm{H} \mathrm{bO}_{2}}$ if $\mathrm{A}, \mathrm{C}$ and $\mathrm{D}$ are calculated correctly.

5. Determine the position of the per cent oxygen saturation values $z, i$. e. their distance in $\mathrm{cm}$ above the baseline of the middle scale, by means of equation [10]. Calibrate the middle scale accordingly.

\section{Appendix}

A relatively simple approach to the construction of a nomogram for the ratio of two variables consists in the logarithmic transformation of the scales. An additional advantage inherent in this procedure is the parallel alignment of the scales, which increases the accuracy of the readings.

For the following discussion, $D_{R}, D_{G}$ and $D_{R} / D_{G}$ are replaced by $x, y$ and $u$. On the different scales, certain logarithmic functions of $x, y$ and $u$ are plotted. These functions will be termed "scale measures".

For the scale measures, we have:

$$
\begin{aligned}
& \text { x-scale: } h_{\mathbf{x}}(s)=p_{\mathbf{x}} \cdot \log s+q_{\mathbf{x}} \\
& \text { y-scale: } h_{\mathbf{y}}(s)=p_{\mathbf{y}} \cdot \log s+q_{\mathbf{y}} \\
& \text { u-scale: } h_{u}(s)=p_{u} \cdot \log s+q_{u}
\end{aligned}
$$

The basic requirement for the construction of a nomogram is that, for all possible values of $x$ and $y$, the point $x$ on the $x$-scale, $y$ on the $y$-scale and the resulting point.u on the u-scale must be 
connectable by a straight line. Algebraically speaking, this requirement means that the following formula must be valid for all values of $x$ and $y$, when $u$ is determined by $x$ and $y$ according to the function $u=u(x, y)$ :

$$
\frac{h_{u}(u(x, y))-h_{x}(x)}{t}=\frac{h_{y}(y)-h_{x}(x)}{T}
$$

In our case, $u(x, y)$ equals $x / y$. If this function and the formulas [13] are inserted into the basic equation [14], we obtain:

$$
\begin{gathered}
\frac{p_{u} \cdot \log x-p_{u} \cdot \log y+q_{u}-p_{x} \cdot \log x-q_{x}}{t}= \\
\frac{p_{y} \cdot \log y+q_{y}-p_{x} \cdot \log x-q_{x}}{T}
\end{gathered}
$$

since $\log x / y=\log x-\log y$.

The equation [15] must be valid for all values of $x$ and $y$. Hence, the coefficients of $\log x$ and $\log y$ and the terms not containing $x$ and $y$ on both sides of [15] must be equal. For the eight parameters $p_{x}, p_{y}, p_{u}, q_{x}, q_{y}, q_{u}, t$ and $T$, we obtain:

$$
\begin{aligned}
& \mathrm{T} \cdot\left(\mathrm{p}_{\mathrm{u}}-\mathrm{p}_{\mathrm{x}}\right)=-\mathrm{t} \cdot \mathrm{p}_{\mathrm{x}} \\
& \mathrm{T} \cdot \mathrm{p}_{\mathrm{u}}=\mathrm{t} \cdot \mathrm{p}_{\mathrm{y}} \\
& \mathrm{T} \cdot\left(\mathrm{q}_{\mathrm{u}}-\mathrm{q}_{\mathrm{x}}\right)=\mathrm{t} \cdot\left(\mathrm{q}_{\mathrm{y}}-\mathrm{q}_{\mathrm{x}}\right) .
\end{aligned}
$$

$\mathrm{I}_{\mathrm{n}}$ addition to [16], certain requirements as to length and range of the scales may be specified. However, such requirements must not conflict with [16].

To fix the end points of the scales, we must return to the original meaning of $x$ and $y, x$ representing the optical density of the sample at 600 and $y$ at $505 \mathrm{~nm}$. For the applications discussed here, $\mathrm{x}$ and $\mathrm{y}$ may vary within the limits

$$
0.1 \leqq \mathrm{x} \leqq 0.6 \text { and } 0.8 \leqq \mathrm{y} \leqq 1.1 \text {. }
$$

If, for instance, we demand $h_{x}(0.1)=0, p_{x}$ and $q_{x}$ must satisfy the condition:

and, since $\log 0.1=-1$,

$$
0=\mathrm{p}_{\mathbf{x}} \cdot \log 0.1+\mathrm{q}_{\mathrm{x}}
$$

$$
\mathrm{p}_{\mathrm{x}}=\mathrm{q}_{\mathrm{x}}
$$

Depending on the required specifications for length and range of the scales, different values for the parameters are obtained. $A^{\text {. }}$ useful solution is obtained if, in addition to $h_{x}(0.1)=0$, we require $h_{y}(1.1)=0$ and utilize simple values for the parameters. Without entering further into the derivation, we give the solution for the scale measures:

$$
\begin{aligned}
& h_{x}(s)=2 \log 10 s \\
& h_{y}(s)=10 \log \frac{1.1}{s} \\
& h_{u}(s)=\frac{10}{6} \log 11 s \\
& T: t=6: 1 .
\end{aligned}
$$

Selecting $15 \mathrm{~cm}$ as a unit, we can easily encompass all three scales into a page size DIN A 4. For the scale values, we obtain the following lengths in $\mathrm{cm}$ :

$$
\begin{aligned}
& h_{x}(s)=30 \log 10 s \\
& h_{y}(s)=150 \log \frac{1.1}{s} \\
& h_{u}(s) \doteq 25 \log 11 s .
\end{aligned}
$$

The scale distance chosen was $T=15 \mathrm{~cm}, t=2.5 \mathrm{~cm}$.

As an example of the calibration of the scales according to [18], we have: On the $x$-scale (representing $D_{R}$ ), the following distance $\mathrm{h}_{\mathrm{x}}$ in $\mathrm{cm}$ above the baseline is obtained for $\mathrm{x}=0.5$ :

$$
\mathrm{h}_{\mathrm{x}}(0.5)=30 \cdot \log 5=20.97 \mathrm{~cm} \text {. }
$$

The calculations of the scale values were performed on a computer in steps of 0.01 , beginning at 0.1 and ending at 0.6 for the $x$-scale $\left(D_{R}\right)$; and beginning at 0.8 and ending at 1.1 for the $y$-scale $\left(D_{G}\right)$. An additional feature of the $y$-scale is that on this scale, the values for $D_{G}$ decrease from below upwards.

This work was supported by the „Schweizerischer Nationalfond zur Förderung der wissenschaftlichen Forschung“, Proj. Nr. 4517.

\section{References}

1. Lundsganad-Hansen, P. and U. Schreiber, diese Z. 6,197 (1968).

Dipl.-Math. H. Ehrengruber Inselspital

CH 3008 Berne (Switzerland)

\title{
Photometrische Mikrobestimmung von Kohlenmonoxid in Luft und Blut
}

\author{
Von G. Ciuhandu und V. Rusu
}

Aus dem Laboratorium für Toxikologie des Institutes für Hygiene (Direktor: Dr. E. Andriescu), Timișoara, Rumänien

(Eingegangen am 18. April 1967)

Die Farbreaktion der alkalischen Lösung von Na-Silbersulfamidbenzoat mit CO gestattet die Bestimmung von CO-Spuren in Luft bzw. im Blut mit einem einfachen Verfahren.

Durch 20stdg. Kontakt von $2 \mathrm{~m} l$ Reagenz mit $10 \mathrm{~m} l$ Luft und nachfolgendes Photometrieren des Reaktionsgemisches bei $420 \mathrm{~nm}$ kann CO in Luft in Konzentrationen von 20-2000 ppm bestimmt werden.

Nach Frcisetzen aus $0,1-0,2 \mathrm{~m} /$ Blut mit Kaliumferricyanid und Saponin und 20stdg. Diffusion in $2 \mathrm{~m} l$ Reagenz kann CO im Blut bis zu 0,2 Vol-\% bestimint werden.

Die Diffusionsdauer kann durch mechanisches Schütteln erheblich abgekürzt werden. Die Reaktion wird nach 5 Stdn. quantitativ und die Steigung der Eichkurve, somit auch die Empfindlichkeit der Bestimmung, wird um etwa $60 \%$ erhöht.

Die Methoden eignen sich gut für Serienbestimmungen.

Traces of $\mathrm{CO}$ in the atmosphere or in blood can be determined by a simplified procedure based on the colour reaction of an alkaline solution of Na-silver-sulphamide-benzoate with $\mathrm{CO}$.

Reagent $(2 \mathrm{ml})$ and air $(10 \mathrm{ml})$ are left in contact for $20 \mathrm{hr}$. The extinction of the solution is then measured at $420 \mathrm{~nm}$. In this way $20-2000$ ppm $\mathrm{CO}$ in the air can be determined.

$\mathrm{CO}$ can be measured in blood down to a concentration of $0.2 \mathrm{Vol}-\% ; 0.1-0.2 \mathrm{ml}$. of blood are treated with potassium ferricyanide and saponin to release the $C O$, which is then diffused over $20 \mathrm{hr}$. into $2 \mathrm{ml}$ of reagent.

The time of diffusion can be considerably reduced by shaking: the reaction is complete after $\mathbf{5}$ hr. and the slope of the calibration curve, and thus the sensitivity, is increased by $60 \%$. The methods are suitable for serial assays. 